\title{
Intense and Extreme Wind Speeds Observed by Anemometer and Seismic Networks: An Eastern U.S. Case Study*
}

\author{
S. C. PRYOR \\ Department of Earth and Atmospheric Sciences, Cornell University, Ithaca, New York \\ R. CONRICK AND C. MiLleR \\ Atmospheric Science Program, Department of Geological Sciences, Indiana University Bloomington, \\ Bloomington, Indiana \\ J. TYTELL \\ University of California, San Diego, La Jolla, California \\ R. J. BARTHELMIE \\ Sibley School of Mechanical and Aerospace Engineering, Cornell University, Ithaca, New York
}

(Manuscript received 14 April 2014, in final form 8 August 2014)

\begin{abstract}
The scale and intensity of extreme wind events have tremendous relevance to determining the impact on infrastructure and natural and managed ecosystems. Analyses presented herein show the following. 1) Wind speeds in excess of the station-specific 95th percentile are coherent over distances of up to $1000 \mathrm{~km}$ over the eastern United States, which implies that the drivers of high wind speeds are manifest at the synoptic scale. 2) Although cold fronts associated with extratropical cyclones are a major cause of high-wind speed events, maximum sustained and gust wind speeds are only weakly dependent on the near-surface horizontal temperature gradient across the front. 3) Gust factors (GF) over the eastern United States have a mean value of 1.57 and conform to a lognormal probability distribution, and the relationship between maximum observed GF and sustained wind speed conforms to a power law with coefficients of 5.91 and -0.499 . Even though there is coherence in the occurrence of intense wind speeds at the synoptic scale, the intensity and spatial extent of extreme wind events are not fully characterized even by the dense meteorological networks deployed by the National Weather Service. Seismic data from the USArray, a program within the Earthscope initiative, may be suitable for use in mapping high-wind and gust events, however. It is shown that the seismic channels exhibit well-defined spectral signatures under conditions of high wind, with a variance peak at frequencies of $\sim 0.04 \mathrm{~s}^{-1}$ and an amplitude that appears to scale with the magnitude of observed wind gusts.
\end{abstract}

\section{Introduction}

Intense and extreme wind events are observed on every continent, derive from multiple scales of forcing, and are manifest across a range of spatial scales. The

\footnotetext{
* Supplemental information related to this paper is available at the Journals Online website: http://dx.doi.org/10.1175/JAMC-D-14-0091.s1.

Corresponding author address: S. C. Pryor, Dept. of Earth and Atmospheric Sciences, Cornell University, Ithaca, NY 14853. E-mail: sp2279@cornell.edu
}

occurrence of intense and extreme wind speeds (defined here as wind speeds in excess of $10 \mathrm{~m} \mathrm{~s}^{-1}$ at $10 \mathrm{~m} \mathrm{AGL}$ and above the 95th percentile, respectively) is associated with a range of ecological impacts [e.g., seed dispersal (Bullock et al. 2012), forest health (Blennow et al. 2010; Gardiner et al. 2000; Peltola et al. 2010), and crop damage (Moore and Osgood 1985)] and with impacts on major energy, transportation, and built-environment infrastructure (Della-Marta et al. 2010; Pryor and Barthelmie 2013a,b; Zhou et al. 2002). The force the wind exerts on any structure scales with the square of the wind speed (Zhou et al.2002); therefore, high-intensity winds over a short duration (i.e., gusts) play a particularly 

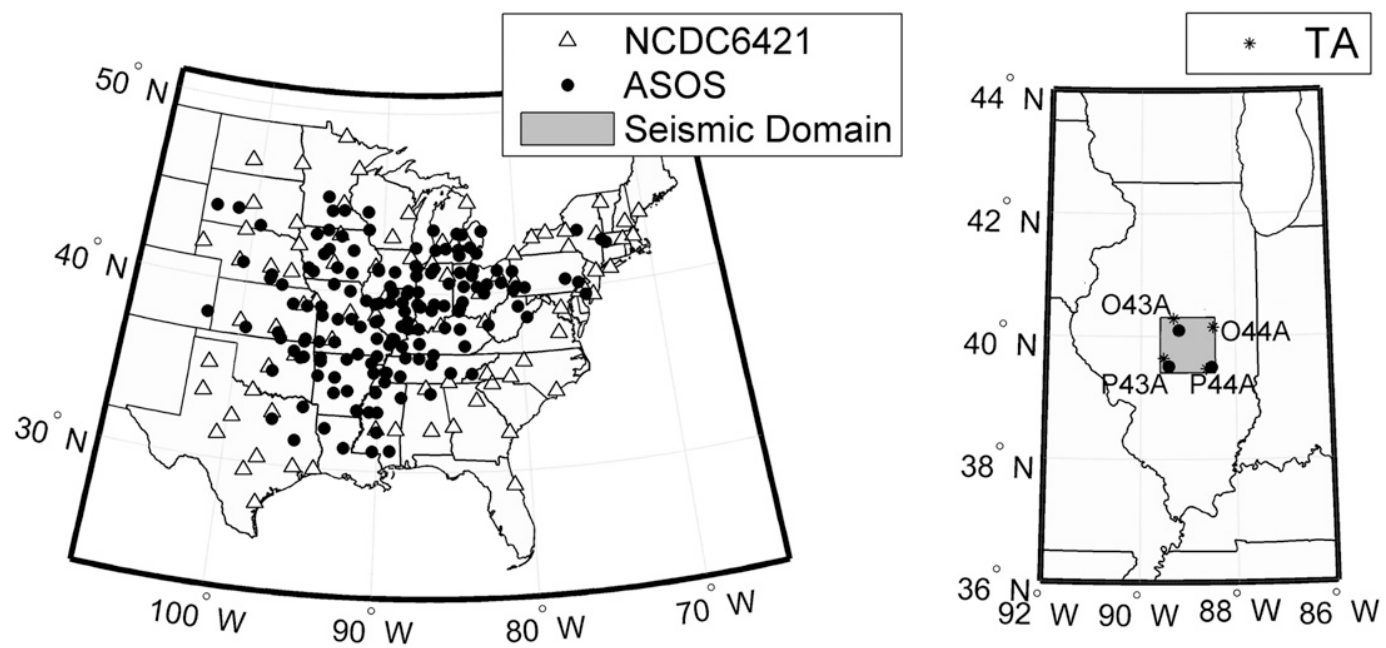

FIG. 1. (left) Map showing the stations from which data are presented. (right) Map of the geographic area chosen for our seismic analysis (central Illinois). The domain contains four TA stations and three ASOS stations within close proximity to the TA stations. The station identifiers and locations of the TA sites are as follows: P43A = Pawnee, IL; P44A = Windsor, IL; O43A = Atlanta, IL; O44A = Mansfield, IL.

important role in wind loading on natural and anthropogenic structures. Thus, improved understanding of the magnitude and spatial coherence of extreme and intense wind events is essential for diagnosing the causes of damaging winds and for projecting their impacts. A further motivation for this analysis derives from evidence of divergent trends in the central tendency and upper tail of the wind speed distribution as observed in historical data (Cusack 2013; Pryor et al. 2009). Decreases in mean wind speeds have been observed in some regions to be linked to increases in local/regional roughness and/or changes in cyclone storm tracks (Vautard et al. 2010), and they have, in some instances, been associated with increases in extreme and intense wind speeds that result from intensification of the hydrological cycle (Huntington 2006) and increased latent heat release in clouds associated with frontal systems such as those studied herein. Therefore, improved understanding of the causes of damaging winds is key to assessing how such events may alter under climate nonstationarity (Cheng et al. 2014; Pryor and Barthelmie 2014; Pryor et al. 2012).

Windstorms are the sixth costliest natural disasters in the United States, with $\$ 311$ million in structural losses every year and an additional $\$ 68$ million in crop losses (Changnon 2011). Indeed, $82 \%$ of all weather "catastrophes" from 1952 to 2006 were accompanied by high wind speeds (Changnon 2009). Downbursts and downdrafts from strong thunderstorms can lead to extreme winds at micro- and mesoscales (Choi and Hidayat 2002; Rauber et al. 2002), and topographically enhanced flows can also lead to intense winds, particularly in the western United States (Changnon 2011). Of the 172 windstorm events during 1972-2006 that were recorded in the contiguous United States, 99 caused major insurance losses (i.e., losses above approximately 1 million in 1951adjusted U.S. dollars) in only one state (Changnon 2009), and a study in central Illinois that was based on data from 1973 to 1979 indicated that $(>96 \%)$ recorded wind events $\geq 18 \mathrm{~m} \mathrm{~s}^{-1}$ had a duration $<1 \mathrm{~h}$ (Changnon 1980). Thus, not all windstorms are of the scale of Winter Storm Kyrill that swept across western, central, and eastern Europe between 17 and 19 January 2007 (Fink et al. 2009). Nevertheless, extratropical cyclones (and frontal activity therein) account for $70 \%$ of all windstorms in the United States (Changnon 2011), and there is evidence that cold fronts characterized by strong horizontal temperature gradients are linked to the occurrence of damaging winds. For example, the 26 March 1991 cold front in the southwestern United States had a temperature gradient of $18^{\circ} \mathrm{C}$ over $100 \mathrm{~km}$ and was associated with wind gusts of $31 \mathrm{~m} \mathrm{~s}^{-1}$ (Sanders 1999).

The overarching objective of this research is to improve understanding of the causes and scales of intense and extreme wind speeds, with a specific focus on the eastern United States. Our study region (Fig. 1) experienced 77 high wind-derived catastrophes during 19722006 (more than one per year, averaging at least $\$ 87$ million in damages per event; Changnon 2009). Herein we conduct a multiscale analysis of both sustained and short-duration (gust) wind extremes, with three main design goals: 
1) The analysis is designed to quantify the spatial coherence of sustained high wind speeds. In addition to offering critical information regarding the dynamical causes of high-wind events, the relevance of extreme wind speeds to socioeconomic sectors such as the insurance industry is dictated in part by the spatial scale over which damage is caused and thus the spatial scales over which high winds are "simultaneously" observed (Chandler et al. 2001).

2) The analysis is designed to quantify characteristics of high-wind events associated with cold-frontal passages. Extratropical cyclones are a major source of high-wind events, and the highest winds are frequently observed at, or close to, cold fronts. Thus mean sustained (2-min average) wind speeds $\bar{U}$ and 3-s gust magnitudes during 35 cold-frontal passages are analyzed to quantify

(i) the relationship between both sustained and gust wind speeds $u_{g}$ and frontal strength,

(ii) the duration of intense sustained wind speeds and gusts, and

(iii) the relationship between mean wind speed and gust magnitudes and to describe the probability distribution of gust factors (GF; defined as the ratio of maximum gust speed to the corresponding mean wind speed).

3) The analysis is designed to assess whether seismic data from the "USArray," a primary program within the National Science Foundation's Earthscope initiative (Lockridge et al. 2012), can be used to map the spatial and temporal scales of extreme wind events. Wind loading leads to the vibration of human structures, which can be measured using seismometers (Trifunac 1970), and seismometers deployed on the Viking mission to Mars showed that the background "noise" in seismic data is correlated with wind gusts (Anderson et al. 1976). Thus, we seek to determine if the seismic data can be used to provide quantitative estimates of wind gusts.

These three objectives thus provide the structure of this paper and are addressed in sections 2,3 , and 4 , respectively. All analyses presented herein are based on wind measurements at $10 \mathrm{~m}$ AGL. Use of measurements at this height affords the best spatial coverage and enables use of long-term datasets, but it is acknowledged that these near-surface wind speeds are also subject to the greatest inhomogeneity as a result of local surface conditions (Azorin-Molina et al. 2014).

\section{Analyses of spatial coherence}

\section{a. Data and method}

Wind speeds from 85 stations within the National Climatic Data Center's “TD-6421” dataset (Groisman 2002) are used in the analysis of spatial coherence. This dataset was selected because it is of relatively long duration ( $>30 \mathrm{yr}$ of data from some stations), and has been subject to detailed data-homogenization and qualitycontrol procedures and has well-documented dataquality flags. The original observations are reported at hourly intervals, and they reflect the mean wind speed [to the nearest $\mathrm{knot}(\mathrm{kt}) ; 1 \mathrm{kt} \approx 0.51 \mathrm{~m} \mathrm{~s}^{-1}$ ] over a 2 -min period during the hour. Data availability increases in 1973 to a point at which $\geq 95 \%$ of stations have more than two-thirds of hourly observations available on a daily basis (see Fig. S1 in the supplemental material). Thus herein we use data from 1973 to 2000 (the end of the dataset).

The spatial coherence of extreme wind events is quantified by selecting a reference station and event threshold to identify the occurrence of "events," and then observations from other stations are examined to determine whether they also exceeded that threshold within a given time period of the event (Pfahl and Wernli 2012; Ricciardulli and Sardeshmukh 2002). This approach quantifies the degree to which the occurrence of extreme values at two or more sites is coherent in time and thus is fundamentally different from spatial correlation analyses that test the degree of coherency of the entire time series. Given the spatial variability of wind speed regimes across the eastern United States (Pryor et al. 2009), as in Pfahl and Wernli (2012) a nonparametric percentile-based definition of extremes was applied. Coherence ratios (CR) are calculated on the basis of station-specific 95th-percentile values. The CR is the relative fraction of extreme events at a target station that occur simultaneously (i.e., within a specified time window) with those at a reference station $\left(\mathrm{CR}=N_{t}^{\operatorname{sim}} / N_{r}\right.$, where $N_{t}^{\text {sim }}$ is the number of events at the target station that occur simultaneously with those at the reference station and $N_{r}$ is the number of events at the reference station). In the initial analysis the time window used is a calendar day, but to examine spatial coherence during translation of synopticscale phenomena $\mathrm{CR}$ are also computed using a temporal window that extends over multiple days and for temporal lags from -2 to +2 days.

Because CR are strongly influenced by the choice of the reference station (and are not symmetric for a given reference and target station pair), in this analysis five reference stations (with low numbers of missing data) are used to allow investigation of spatial variability across the study domain by using stations with very low numbers of missing data. The specific locations used as reference stations are as follows: Louisville Standiford Field (World Meteorological Organization identifier 724230) in Kentucky is selected because of its central location within the study region. Abilene Municipal 
(a) Pierre

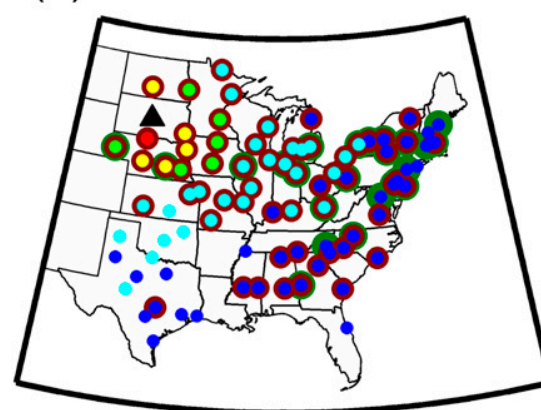

(b) Albany

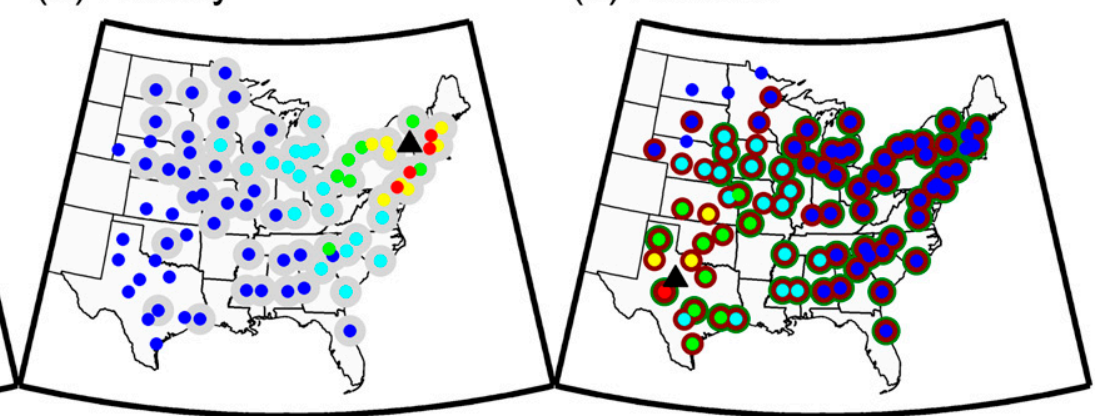

(c) Abilene (d) Louisville

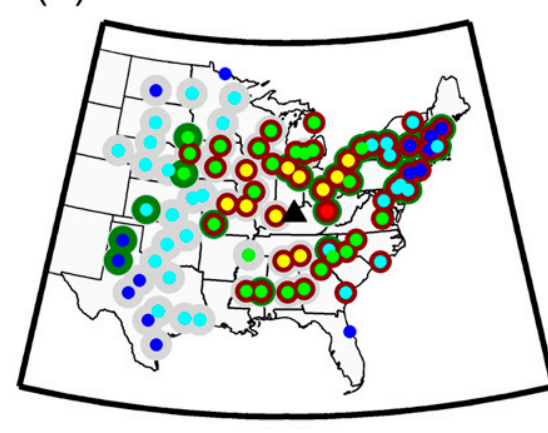

(e) Athens

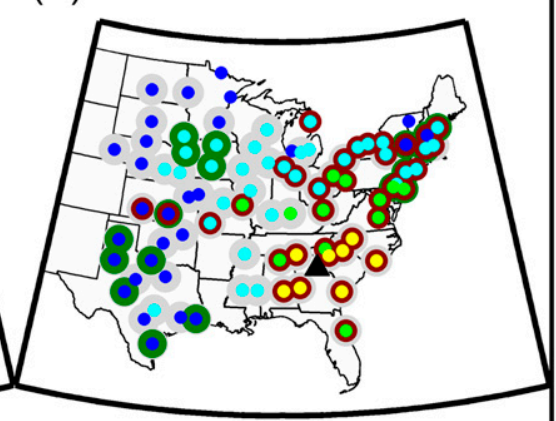

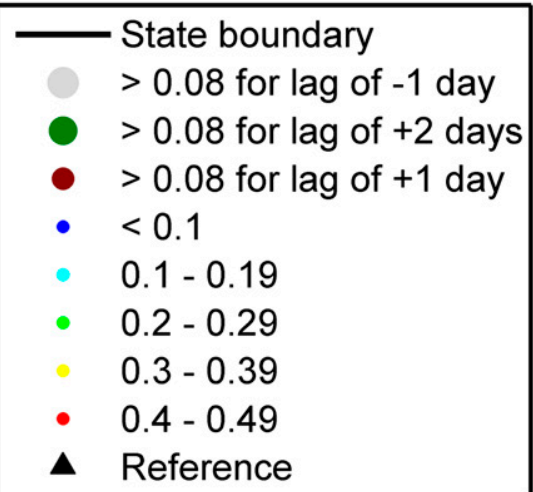

FIG. 2. Coherence ratios for each station in the NCDC TD-6421 dataset calculated on the basis of extreme wind events at (a) Pierre Municipal Airport (726686), (b) Albany County Airport (725180), (c) Abilene Municipal Airport (722660), (d) Louisville Standiford Field (724230), and (e) Athens Ben Epps Airport (723110). The color of the inner symbol indicates the same-day CR. The outer rings indicate those stations that exhibit CR $>0.08$ for a lag of +1 day (in dark red) [excluded in (b)], +2 days (in dark green) [excluded in (b)], and -1 day (in gray) [(b),(d), and (e) only].

Airport (722660) in Texas and Pierre Municipal Airport (726686) in South Dakota are located in the west of the domain and are used to investigate the effect of lee cyclogenesis from the Rocky Mountains (Hobbs et al. 1996) on spatial coherence. Athens Ben Epps Airport (723110) in Georgia and Albany County Airport (725180) in New York are selected to investigate extreme wind events in the southeastern and the northeastern United States, respectively (see Fig. 2). For Louisville (724230) and Athens (723110), CR are also calculated for lags of $-2,-1,+1$, and +2 days relative to the occurrence of an event at these reference stations. At Abilene (722660) and Pierre (726686), CR are only calculated for one and two days after the day of the event at these reference stations because of their western location. For Albany (725180), CR are only calculated for one and two days prior because of its northeastern location. Same-day coherence ratios are also calculated for the cold season (October-February) when thunderstorms are less likely (Easterling and Robinson 1985) to determine the degree to which the coherence differs during the least convective part of the year.
Temporal autocorrelation in the time series of threshold exceedance is relatively weak and is neglected in the analyses to determine the spatial coherence ratios that would derive from random chance. Weibull distributions having shape and scale factors calculated from the wind speed data at the five reference stations are used with a random-number generator to derive $1000 \times 5$ simulated daily maximum wind speed time series of 10200 value duration (i.e., 1000 realizations of $28 \mathrm{yr}$ of data from each of the five stations). These time series are then used to determine coherence ratios. The results indicate that CR $>$ 0.08 is observed in less than $1 \%$ of analyses of the simulated time series, and thus $\mathrm{CR}>0.08$ are considered to be statistically different from 0 at the $99 \%$ confidence level.

\section{b. Results}

Same-calendar-day coherence ratios for the most centrally located reference station, Louisville (724230), exhibit an almost omnidirectional pattern and are typically higher for moderate station spacing $(<400 \mathrm{~km}$; Fig. 2d) than CR from the other reference stations, 
which exhibit clear directional bias in the CR patterns (Fig. 2). For Pierre (726686) CR tend to be highest in a swath extending east (across the northern and central plains; Fig. 2a), consistent with tracking of midlatitude cyclones to the east (Hoskins and Valdes 1990). For Abilene (722660), the region of highest CR tends to extend along a north-south axis (Fig. 2c), which may reflect the influence of the low-level jet (Whiteman et al. 1997) or southward-extending drylines and strong low-level jets associated with lee cyclogenesis east of the Rocky Mountains (Hagemeyer 1991; Hoch and Markowski 2005). Albany (725180) exhibits high CR with other stations along the East Coast, except for the station on Long Island and the station in northern Vermont, both of which have CR $<$ 0.3 , possibly indicating local channeling of the flow by the coastline and/or topographic features (Fig. 2b). For Athens (723110) the CR exhibit lowest values for even comparatively nearby stations, indicating that smallerscale features (e.g., localized severe convection and related downdrafts and/or downbursts; Smith et al. 2013) may be responsible for a larger fraction of the intense wind speeds in this region (Fig. 2e).

Consistent with expectations that are based on extratropical cyclone frequencies, tracks, and translational speeds (Coleman and Klink 2009), spatial coherence ratios for a lag of +1 day for Pierre (726686) are $>0.08$ for a swath of stations to the east (Fig. 2a), but stations exhibiting coherence ratios of $>0.08$ for a +2 -day lag are generally limited to the Great Lakes and the East Coast. Coherence ratios for Abilene (722660) exhibit many more values $>0.08$ at both +1 - and +2 -day lags (Fig. $2 \mathrm{c}$ ) possibly because of slower translational speeds for cyclones originating in Colorado and tracking to the northeast, in contrast with faster-moving Alberta clippers that tend to follow more zonal tracks (Thomas and Martin 2007) and may have a greater influence on the more northerly stations (cf. Fig. 2a vs Fig. 2c). Spatial patterns of lagged coherence ratios from Louisville (724230) and Athens (723110) (Figs. 2d,e) are similar and both exhibit coherence ratios $>0.08$ for a +1 -day lag with a large swath of stations to the north and east. Significant coherence ratios at a +2 -day lag are generally located well northeast of Athens, whereas they are closer but still generally to the north and east of Louisville (cf. Fig. 2d vs Fig. 2e). This may be an impact of coastal lows generally moving faster than systems migrating through the Great Lakes and Ohio valley. The -1-day lag for Albany (725180) shows widespread CR $>0.08$ (Fig. 2b) with the exception of the southern Great Plains, which is consistent with cyclone tracks converging on the northeastern United States (Coleman and Klink 2009). A similar situation is seen for Athens, with -1 -day-lag CR $>0.08$ widespread across the study area with the exception of the midAtlantic region and the Northeast (Fig. 2e).

Although the spatial patterns of same-day CR in the current analysis vary from site to site, analyses for these five reference stations indicate an approximately exponential decay with distance and a drop in CR to below 0.1 at spherical distances of approximately $1200 \mathrm{~km}$ (Fig. 3a). Thus the spatial scales of coherence reported herein are larger than those derived from analyses of damage patterns associated with winter windstorms in the contiguous United States, which suggested $10 \%$ cause damage over spatial scales $>250000 \mathrm{~km}^{2}$ (a radial coherence of $\sim 500 \mathrm{~km}$; Changnon 2011). Our results differ from those of Changnon (2011) in part because his study reflects the occurrence of short-term pseudogust wind speeds $\geq 20 \mathrm{~m} \mathrm{~s}^{-1}$, whereas our approach focuses on a percentile-based threshold of 2-min mean wind speeds. Coherence ratios calculated using a temporal window of \pm 2 days for Athens (723110) and Louisville (724230) naturally exceed those for the same day and are $>0.50$ at all other stations for distances up to nearly $600 \mathrm{~km}$ (Fig. 3a). These results are qualitatively similar to analyses of the 99th-percentile daily peak wind gust in Switzerland and Germany within a \pm 2 -day lag that found spatial coherence ratios of $>0.35$ at distances up to $600 \mathrm{~km}$ (Pfahl and Wernli 2012). The high spatial coherence of intense winds demonstrated herein implies a strong synoptic-scale driver of high-wind events, may indicate high potential predictability, and has implications for preferred functional form and predictors used in statistical models applied to downscaling analyses of intense and extreme wind events (Pryor and Barthelmie 2014).

Higher spatial coherence of intense winds is observed during the cold season than during the entire year (cf. Fig. 3a and Fig. 3b), particularly in the Southeast (cf. Fig. 2e and Fig. 4e). When averaged across all stations, coherence ratios decline almost exponentially with station separation (distance) and are slightly higher for cold-season events than in events from the entire year (Fig. 3b). This is also true for individual stations except in data from Albany (725180), for which CR are slightly lower on average for distances of $500-1000 \mathrm{~km}$ in the cold season than they are in data from the entire calendar year. This result is consistent with the a priori expectation that the occurrence of high wind speeds associated with deep convection events lowers CR (and is least likely in Albany) and with analyses of both windstorm dimensions (Changnon 2011) and rainfall coherence in the southeastern United States (Baigorria et al. 2007). The spatial patterns of coherence in the cold season are similar to those derived using data from the entire year (cf. Figs. 2 and 4). During the cold season, however, there 

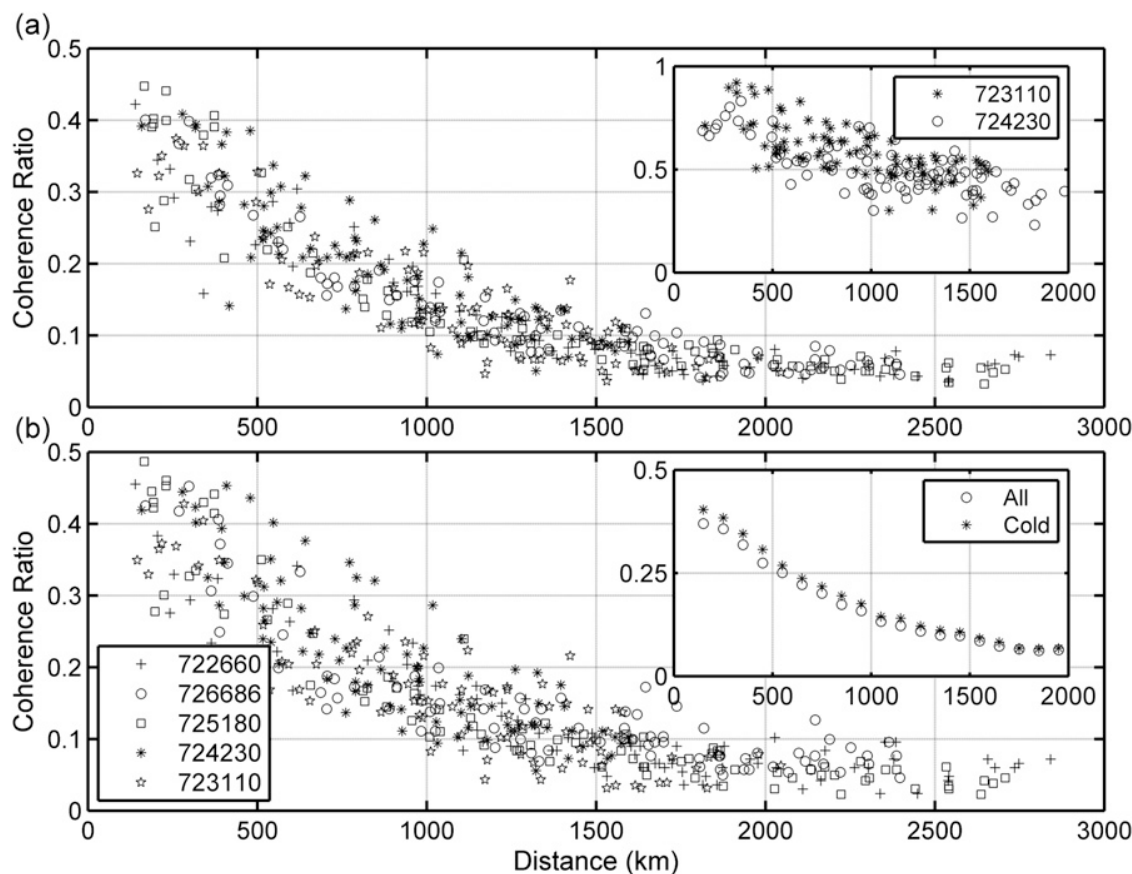

FIG. 3. Same-day coherence ratios and distance from reference stations from the NCDC TD6421 dataset for (a) the entire 1973-2000 dataset and (b) just cold-season events (OctoberFebruary). Inset in (a): coherence ratios for Louisville (724230) and Athens (723110) calculated by including all extreme wind events at other stations within a \pm 2 -day lag. Inset in (b): mean coherence ratios for all stations in 100-km distance bins calculated for the entire dataset and for cold-season events only.

is a notable decrease in the number of stations with $\mathrm{CR}>$ 0.08 for Albany at the -1 -day lag (cf. Fig. 2b and Fig. 4b). This result may reflect the role of faster-moving coastal lows (Bernhardt and DeGaetano 2012) in generating high-wind events in the Northeast during the cold season.

\section{Analysis of sustained and gust wind speeds associated with cold fronts}

\section{a. Data and method}

The high degree of spatial coherence (i.e., coherence on scales of hundreds of kilometers) in the occurrence of intense wind speeds is consistent with a priori expectations regarding the importance of extratropical cyclones and cold-frontal passages to the occurrence of high wind speeds over the eastern United States. Thus an analysis was undertaken to describe wind speeds and gusts associated with cold-frontal passages that occurred from 1 January 2012 to 1 September 2013. The study domain for this analysis was centered on Illinois and used hourly surface meteorological data from National Weather Service (NWS) Automated Surface Observing System (ASOS) observing sites (Fig. 1). ASOS data were extracted on the basis of identification of cold fronts (identified using the
Hydrometeorological Prediction Center's Daily Weather Maps; http://www.hpc.ncep.noaa.gov/dailywxmap/) and were used to characterize the frontal intensity and wind characteristics along three transects perpendicular to each front (separated by $\geq 100 \mathrm{~km}$ to ensure that wind and other data are representative of the entire front).

ASOS sustained mean wind speeds are also 2-min mean values, and they are reported between 50 and 59 min past the hour. Wind gusts are recorded if the peak 3 -s wind speed $\geq 14 \mathrm{kt}\left(\sim 7 \mathrm{~m} \mathrm{~s}^{-1}\right)$. All wind speed and gust measurements are reported as integer values in knots (NOAA 1998). An a priori expectation of our analysis is that wind speed and gust magnitudes are determined, at least in part, by frontal strength. Thus, as part of this analysis, frontal strength (described by the surface horizontal temperature gradient across a cold front, i.e., $d T / d n)$ is calculated from 1200 UTC measurements at ASOS stations on both sides of, and perpendicular to, the cold front. Ill-defined fronts with a $d T / d n<0.014^{\circ} \mathrm{C} \mathrm{km}^{-1}$ are excluded from the analysis, leaving 35 events for analysis herein that exhibit a diverse range of frontal strengths (range of $d T / d n$ : from 0.016 to $0.051^{\circ} \mathrm{Ckm}^{-1}$; mean of $d T / d n \approx$ $0.030^{\circ} \mathrm{C} \mathrm{km}^{-1}$, with standard deviation $\sigma \approx 0.01^{\circ} \mathrm{C} \mathrm{km}^{-1}$; median $\approx 0.026^{\circ} \mathrm{Ckm}^{-1}$; mode $\approx 0.035^{\circ} \mathrm{C} \mathrm{km}^{-1}$ ). Data for gust and sustained wind speed from these frontal-passage 
(a) Pierre

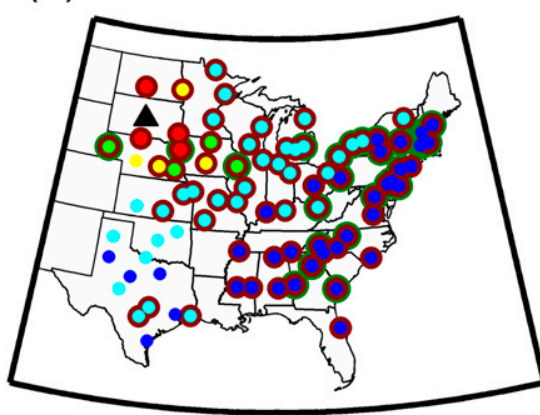

(b) Albany

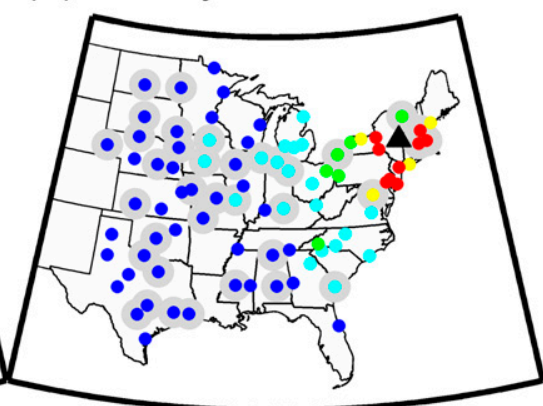

(c) Abilene

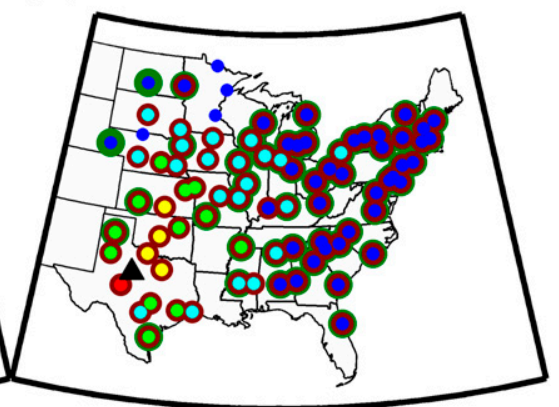

(d) Louisville

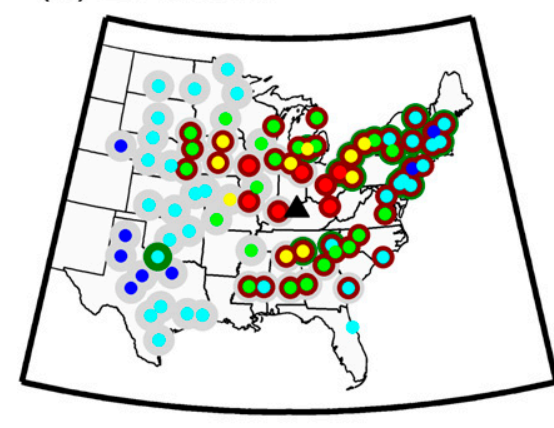

(e) Athens

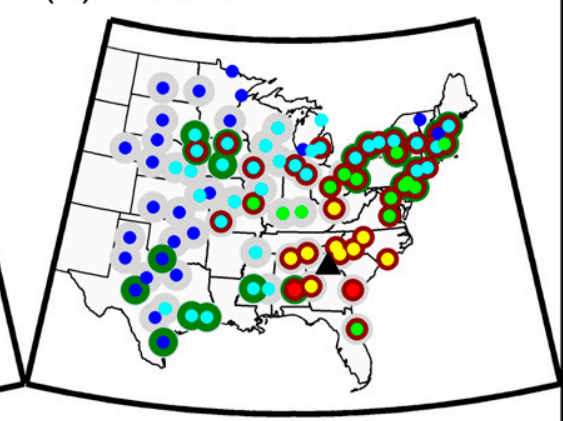

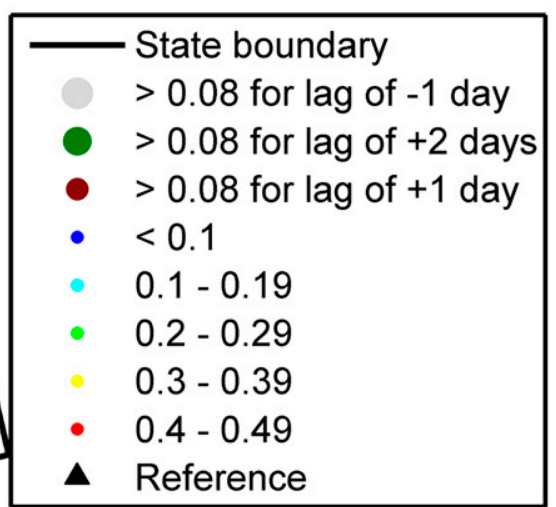

FIG. 4. As in Fig. 2, but for the cold-season (October-February) events.

case studies are also used to investigate the duration of high-wind speed events, to characterize the probability distribution of GF, and to describe the dependence of GF on sustained wind speed.

\section{b. Results}

Although maximum wind speeds and gusts increase with frontal strength, linear regression fits of both maximum sustained wind speeds and wind gusts with $d T / d n$ exhibit variance explanation $r^{2}$ of $<0.02$ (Fig. 5a). Therefore, this metric of frontal intensity is a very weak predictor of wind extremes. This finding may be due to use of a single value to describe frontal strength (thus neglecting variability along the front and/or temporal evolution of the front). It may also reflect the diversity of factors that determine the surface thermal gradient across a front (including local land cover variability and the presence/absence of cold cloud; Segal et al. 1993), or that mechanisms responsible for vertical momentum transport and thus for high near-surface wind speeds (Brasseur 2001) are not strongly correlated with this measure of frontal intensity.

Forest damage can begin at wind speeds as low as $10 \mathrm{~m} \mathrm{~s}^{-1}$ (Gardiner et al. 2000; Peltola 2006) and, like other impacts, is determined, in part, by the duration of time that the high wind speeds are sustained. Sustained mean wind speeds $\bar{U}>10 \mathrm{~m} \mathrm{~s}^{-1}$ are observed for at least one station during each of the 35 cold-frontal events. Over $37 \%$ of periods with $\bar{U}>10 \mathrm{~m} \mathrm{~s}^{-1}$ lasted $\geq 2 \mathrm{~h}$, and approximately $15 \%$ lasted $\geq 3 \mathrm{~h}$ (Fig. 5b). High-magnitude positive exertions of the wind are also observed to occur over multiple hours. Over one-half of occasions with wind gusts (3-s sustained wind speeds $u_{g}$ ) $>10 \mathrm{~m} \mathrm{~s}^{-1}$ have $\geq 2$-h duration (Fig. 5b). This result is consistent with the analysis of spatial coherence, which implies a large-scale driver of extreme wind speeds and therefore that the conditions associated with large-magnitude wind gusts may be sustained over many hours.

Gust factors (typically defined as $u_{g} / \bar{U}$ ) are used extensively in wind-load design codes (although the structural elemental under consideration dictates the GF-loading constants; Greenway 1979). For example, a GF of 1.43 (for 3 -s gust to 10 -min sustained wind speeds at $10-\mathrm{m}$ height) is typically used in estimating dynamic loads exerted by wind gusts on components of an electrical transmission line (Wong and Miller 2010). The GF are a function of the turbulence length scales of the flow (Greenway 1979) [and thus the surface over which the flow is moving, atmospheric stratification, and measurement height (Paulsen and Schroeder 2005)], instrument response (Kristensen 1998), and the averaging period that is used to characterize gust and sustained mean wind speed (Kristensen et al. 1991) 

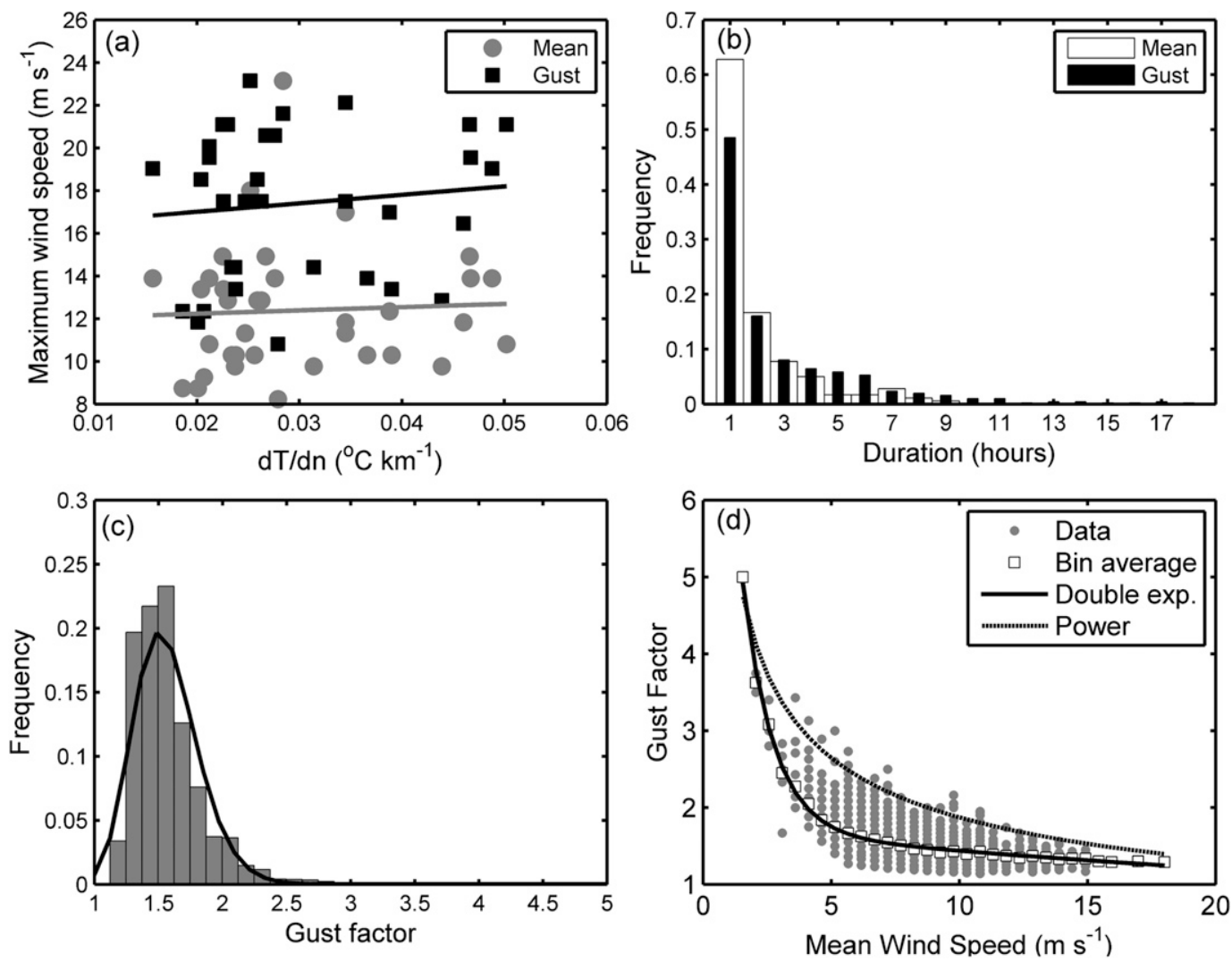

FIG. 5. Statistics of sustained and gust wind speeds as measured at ASOS stations during the 35 cold-frontal events. (a) Maximum sustained and gust wind speeds as a function of $d T / d n$. The lines denote linear-regression fits to the data $(y=m x+c)$ that have the following parameters: for sustained wind, $m=15.2, c=11.9, r^{2}<0.01$; for gust, $m=39.8, c=16.2, r^{2} \approx 0.01$. (b) Duration of consecutive hours with mean sustained and gust wind speeds $\geq$ $10 \mathrm{~m} \mathrm{~s}^{-1}$. (c) Frequency distribution of all GF reported for observations with nonzero gust magnitudes (sample size $=$ 2662). The mean, median, and modal values are 1.57, 1.5, and 1.5, respectively. Also shown (by the solid line) is a lognormal distribution $\left\{y=f(x \mid a, b)=\left[x b(2 \pi)^{1 / 2}\right]^{-1} x^{-(\ln x-a)^{2} /\left(2 b^{2}\right)}\right\}$, where $a=0.437(0.431,0.443)$ and $b=0.160$ $(0.156,0.165)$, with the $95 \%$ confidence intervals on $a$ and $b$ given in parentheses. (d) Scatterplot of mean sustained wind speed $\bar{U}\left(\mathrm{~m} \mathrm{~s}^{-1}\right)$ and GF. A double-exponential fit to the mean values of GF in each sustained wind speed $\left[y=f(x \mid a, b, c, d)=a e^{b x}+c e^{d x}\right]$ is shown by the solid line and has the following parameters: $a=11.79(10.70$, $12.88), b=-0.832(-0.891,-0.773), c=1.71(1.62,1.80)$, and $d=-0.0177(-0.0222,-0.0131)$. A power-law fit to the maximum GF for each sustained wind speed is shown by the dashed line and has the form $\left[y=f(x \mid a, b)=a x^{b}\right]$, where $a=5.91(5.46,6.35)$ and $b=-0.499(-0.543,-0.455)$. Note that because of the truncation of the observations to the nearest knot the gust and sustained wind speeds and the GF derived therefrom are not continuous variables but rather conform to a time series of discrete (but noninteger) values $\left(\mathrm{m} \mathrm{s}^{-1}\right)$.

(Table 1). For the 2661 gust observations in this study, the mode and median $\mathrm{GF}=1.5$ and the mean $=1.57$ (Fig. 5c). Although differences in averaging period confound detailed comparisons with prior studies, these values are in reasonable accord with previous estimates of GF for extratropical cyclones (Table 1) and corroborate research that has suggested that GF from extratropical cyclones may exceed those from tropical systems (Paulsen and Schroeder 2005). The probability distribution of GF (at 10-m AGL) is highly positively skewed and is best described by a lognormal distribution (Fig. 5c).

Prognostic gust forecasting, although of high potential utility, is extremely challenging (Thorarinsdottir and
Johnson 2012), in part because the relationship between GF and $\bar{U}$ is highly nonlinear and is a function of measurement height (Agustsson and Olafsson 2004; Cheng et al. 2012; Krayer and Marshall 1992; Paulsen and Schroeder 2005). Consistent with prior research, the majority of high GF are associated with relatively weak mean sustained wind speeds. For $\bar{U}>10 \mathrm{~m} \mathrm{~s}^{-1}$ all GF are $<2$ (Fig. 5d). The relationship between maximum daily $G\left[G=\left(u_{g} / \bar{U}\right)-1\right.$, where $u_{g}=$ peak daily gust velocity and $\bar{U}=$ mean daily wind speed] and $\bar{U}(\mathrm{kt})$ in a prior study of measurements in the ChampaignUrbana metropolitan area in Illinois fitted a power law with scale and power coefficients of 7.072 and -0.746 , 
TABLE 1. Mean GF at $\sim 10 \mathrm{~m}$ AGL from this study and previous analyses, along with information regarding the averaging periods used. Note that the type of anemometers deployed in these studies varied greatly and thus some of the differences between the GF may drive from variations in data quality in addition to variations in the averaging periods.

\begin{tabular}{lccc}
\hline \hline \multicolumn{1}{c}{ Study } & $\begin{array}{c}\text { Gust } u_{g} \text { averaging } \\
\text { period (s) }\end{array}$ & $\begin{array}{c}\text { Sustained wind speed } \\
\bar{U} \text { averaging period (s) }\end{array}$ & Mean GF \\
\hline This analysis & 3 & 120 & 1.57 \\
Canada Wind and Wave Climate Atlas (Canada & 3 & 3600 & 1.34 \\
$\quad$ Transportation Development Centre 1991) & 3 & 3600 & 1.5 \\
U.K. structural design (Cook 1986) & 3 & 600 & 1.56 for $\bar{U} \geq 25 \mathrm{~m} \mathrm{~s}{ }^{-1}$; \\
Tropical cyclone (Krayer and Marshall 1992) & 2 & 3600 & $\mathrm{GF}=1.54$ \\
& & 600 & 1.4 and 1.7 \\
Mixed climate (Yu and Chowdhury 2009) & 3 & 600 & 1.59 \\
Extratropical cyclones (Paulsen and Schroeder 2005) & 2 & 600 & 1.35 \\
Tropical cyclones (Paulsen and Schroeder 2005) & 2 & 600 & 1.40 \\
Extratropical cyclones (Durst 1960) & 2 & 600 & 1.33 \\
Tropical cyclones (He et al. 2013) & 3 & 600 & 1.24 \\
Monsoon winds (He et al. 2013) & 3 & 600 & 1.93 \\
Thunderstorm (Choi and Hidayat 2002) & 3 & 3 & 1.72 \\
Nonthunderstorm (Choi and Hidayat 2002) & & &
\end{tabular}

respectively (Weggel 1999). Analysis of the multistation hourly data considered herein within this framework yields similar coefficients of 6.360 and -0.947 but implies that simultaneously observed gusts exhibit a more rapid decline with increasing 2-min mean wind speeds (as used herein) than with daily mean wind speeds. A double-exponential fit to the more conventional definition of GF as a function of $\bar{U}$ is shown in Fig. 5d, along with a power-law fit to the upper envelope of the conditional probability $(\mathrm{GF} \mid \bar{U})$ [scale parameter $=5.91$ (95\% confidence interval is from 5.46 to 6.35 ); power coefficient $=-0.499$ (95\% confidence interval is from -0.543 to -0.455$)]$. Although the range of 2-min sustained mean wind speeds in this analysis is relatively small $\left(\bar{U}<19 \mathrm{~m} \mathrm{~s}^{-1}\right)$, this relationship may have utility as a first-order predictor of nonthunderstorm maximum GF for a given sustained mean wind speed. The scatter shown in Fig. 5d is illustrative of a high degree of spatial variability in GF, which derives in part from local land surface impacts on gusts, but is also symptomatic of subsynoptic-scale variability in the intensity of highwind events.

\section{Can seismic data be used to identify and quantify extreme wind events?}

\section{a. Data and method}

Even the approximately 900 stations that compose the ASOS network in the United States (area $\approx 9.8 \times$ $10^{6} \mathrm{~km}^{2}$ ) undersample some extreme wind events and may be insufficient to quantify the spatial and temporal scales of gust events. It has long been known that strong wind events impart a force onto the ground that, in turn, causes ground accelerations (and thus a seismic response;
Anderson et al. 1976). Indeed, variations in atmospheric pressure, temperature, and wind are often identified as causing interference in interpreting data from seismometers, particularly at periods $>10 \mathrm{~s}$ (De Angelis and Bodin 2012). As a result, seismologists have developed a range of techniques to reduce this long-period "noise" from seismic records (see references in De Angelis and Bodin 2012). Here we invert this "problem" and instead provide an initial assessment of whether seismic data from the very high density USArray (Lockridge et al. 2012), and potentially from other seismic arrays, might be used to characterize, map, and quantify extreme wind events, with a particular focus on gust events.

The Transportable Array (TA) network comprises 400 seismic stations deployed within vault enclosures $(\sim 2.1 \mathrm{~m}$ deep, with inner diameter $\approx 1 \mathrm{~m})$ that are sequentially deployed with a Cartesian grid spacing of $\sim 70 \mathrm{~km}$ throughout the contiguous United States. Starting in early 2010, TA installations also include barometric pressure gauges. These installations were in place for approximately 2 years before being moved and installed along the eastern edge of the array footprint (the TA network is currently deployed along the East Coast of the United States).

Data from two case studies (11-12 November 2012 and 18-19April 2013) of cold-frontal passages within a $100 \mathrm{~km} \times$ $100 \mathrm{~km}$ subdomain focused on a flat homogenous region in central Illinois (Fig. 1) are presented here. Data from ASOS stations are used to identify a 2-h window during which the cold front passed over the subdomain and a 1-2-h period of quiescent winds during the same 48-h period. Data from a microbarometer deployed at each TA station along with the $40-\mathrm{Hz}$ data from the BHZ (broadband high-gain seismometer vertical ground acceleration), 
TABLE 2. Wind speeds at the ASOS stations location at KSPI and KDEC during the seismic case studies shown in Fig. 6. With the exception of the calm period during 11 Nov 2012, a 2-h window is used in the frequency analysis; for 11 Nov 2012, only $1 \mathrm{~h}$ of data is used to represent "quiescent" conditions. Here, $\bar{U}$ is the mean 2-min wind speed $\left(\mathrm{m} \mathrm{s}^{-1}\right)$, and $u_{g}$ is the 3 -s gust wind speed $\left(\mathrm{m} \mathrm{s}^{-1}\right)$.

\begin{tabular}{|c|c|c|c|c|c|c|}
\hline & \multicolumn{3}{|c|}{ High wind } & \multicolumn{3}{|c|}{ Relatively calm } \\
\hline & Time (UTC) & $\bar{U}$ & $u_{g}$ & Time (UTC) & $\bar{U}$ & $u_{g}$ \\
\hline \multicolumn{7}{|c|}{11 Nov 2012} \\
\hline KSPI & 2052 & 26 & 37 & 0752 & 15 & - \\
\hline KSPI & 2152 & 12 & - & & & \\
\hline KDEC & 2054 & 20 & 31 & 0754 & 16 & - \\
\hline KDEC & 2154 & 21 & 33 & & & \\
\hline \multicolumn{7}{|c|}{ 18-19 Apr 2013} \\
\hline KSPI & $035219 \mathrm{Apr}$ & 19 & 30 & $125218 \mathrm{Apr}$ & 8 & - \\
\hline KSPI & $045219 \mathrm{Apr}$ & 17 & 25 & $135218 \mathrm{Apr}$ & 4 & - \\
\hline KDEC & 035419 Apr & 13 & 25 & $125418 \mathrm{Apr}$ & 9 & - \\
\hline KDEC & 045419 Apr & 19 & 27 & $135218 \mathrm{Apr}$ & 9 & - \\
\hline
\end{tabular}

BHE (west-east ground acceleration), and BHN (southnorth ground acceleration) seismic channels were despiked, detrended, subjected to fast Fourier transform, and used to construct power spectra for the conditionally sampled data periods.

\section{b. Results}

Measuring turbulent pressure fluctuations is challenging (Wilczak and Bedard 2004), but all power spectra of data from microbarographs deployed at each TA station show increased variance in a broad frequency range centered between 0.1 and $0.01 \mathrm{~Hz}$ during high-wind periods that is not present during the period of quiescent winds (see Fig. S2 in the supplemental material). Data from all seismic channels show the emergence of a more distinct variance peak at a frequency centered at $\sim 0.04 \mathrm{~Hz}$ (i.e., periods of $\sim 25 \mathrm{~s}$ ) during the gust/frontal-passage periods that is not present during relatively quiescent winds (see Table 2 and Fig. 6). The frequencies of enhanced variability are consistent between the two case studies and are displaced to lower frequencies than gust phenomena (time scales $\approx 3-5 \mathrm{~s}$ ). Further, this peak is recorded at distinctly different frequencies than is the peak of high variance (centered on periods of $\sim 100-400 \mathrm{~s}$ ), referred to historically as "the earth's hum," that is thought to arise from the interaction of oceanic waves on continental shelves (De Angelis and Bodin 2012). Seismic responses to wind gusts exhibit the clearest signal in the BHZ channel (associated with vertical motion; Figs. $6 \mathrm{c}, \mathrm{f}$ ). The amplitude of the variance maximum in $\mathrm{BHZ}$ that is associated with frequencies of $\sim 0.04-0.06 \mathrm{~Hz}$ is larger in the 11 November 2012 event than for the 18-19 April 2013 cold front. The variance [expressed as $f \times S(f)$ ] at $f \approx 0.044-0.052 \mathrm{~Hz}$ from the four seismic stations during the period of highest wind speeds and gusts on 11 November 2012 is $(1.4-1.8) \times 10^{7} \mathrm{n} \mathrm{m}^{2} \mathrm{~s}^{-3}$, whereas during the period of relatively quiescent winds it is $(0.1-49) \times$ $10^{3} \mathrm{n} \mathrm{m}^{2} \mathrm{~s}^{-3}$. Similar data for 18-19 April 2013 indicate values of $(0.8-1.2) \times 10^{6} \mathrm{n} \mathrm{m}^{2} \mathrm{~s}^{-3}$, whereas during the period of relatively quiescent winds it is $(0.1-5) \times 10^{3} \mathrm{n} \mathrm{m}^{2} \mathrm{~s}^{-3}$. These values are consistent with the higher gust speeds reported at ASOS stations within the study domain during the November event $\left(\sim 34 \mathrm{~m} \mathrm{~s}^{-1}\right)$ relative to the April event $\left(\sim 27 \mathrm{~m} \mathrm{~s}^{-1}\right)$. The higher background signal and site-to-site variability even during the relatively quiescent period on 11 November 2012 is reflective of relatively high wind speeds during that period $(\sim 15-$ $16 \mathrm{~m} \mathrm{~s}^{-1}$ ), but it does not mask the gust signal (Table 2; Fig. 6). These case studies cannot be used to definitively propose a scaling between seismic response and gust wind speeds, but they indicate the potential for use of data from the USArray (or other seismic arrays) in analyzing and mapping wind extremes.

\section{Concluding remarks}

On the basis of the analyses presented herein, the following inferences are drawn regarding the causes and scales of intense and gust wind events over the eastern United States:

1) Exceedance of site-specific 95th-percentile wind speeds is coherent over distances up to $1000 \mathrm{~km}$ and exhibits the largest "footprints" during the cold season. These results thus emphasize the importance of synoptic-scale drivers of intense wind events. Coherence ratios exhibit spatial patterns that are in accord with a priori expectations regarding translational tracks and speeds of extratropical cyclones, indicate that deep convection lowers CR during the warm season (particularly in the southeastern United States), and imply that fast-moving coastal lows are responsible for a large number of extreme wind events during the cold season in the northeastern United States.

2) Cold fronts are a major cause of high-wind speed events, but-although maximum 2-min sustained and 3-s gust wind speeds tend to increase with frontal intensity (temperature gradient across the front)the relationship is not statistically significant at the $80 \%$ confidence level. Three-second gusts exceeding $10 \mathrm{~m} \mathrm{~s}^{-1}$ occur over 2 or more consecutive hours at a given site in over $50 \%$ of cases and can extend up to $18 \mathrm{~h}$ in duration, again indicating a large-scale driver of intense wind speeds. Gust factors associated with frontal cyclones exhibit a nonlinear relationship with sustained wind speed. The mean GF over the eastern United States is 1.57, which is in good agreement with 

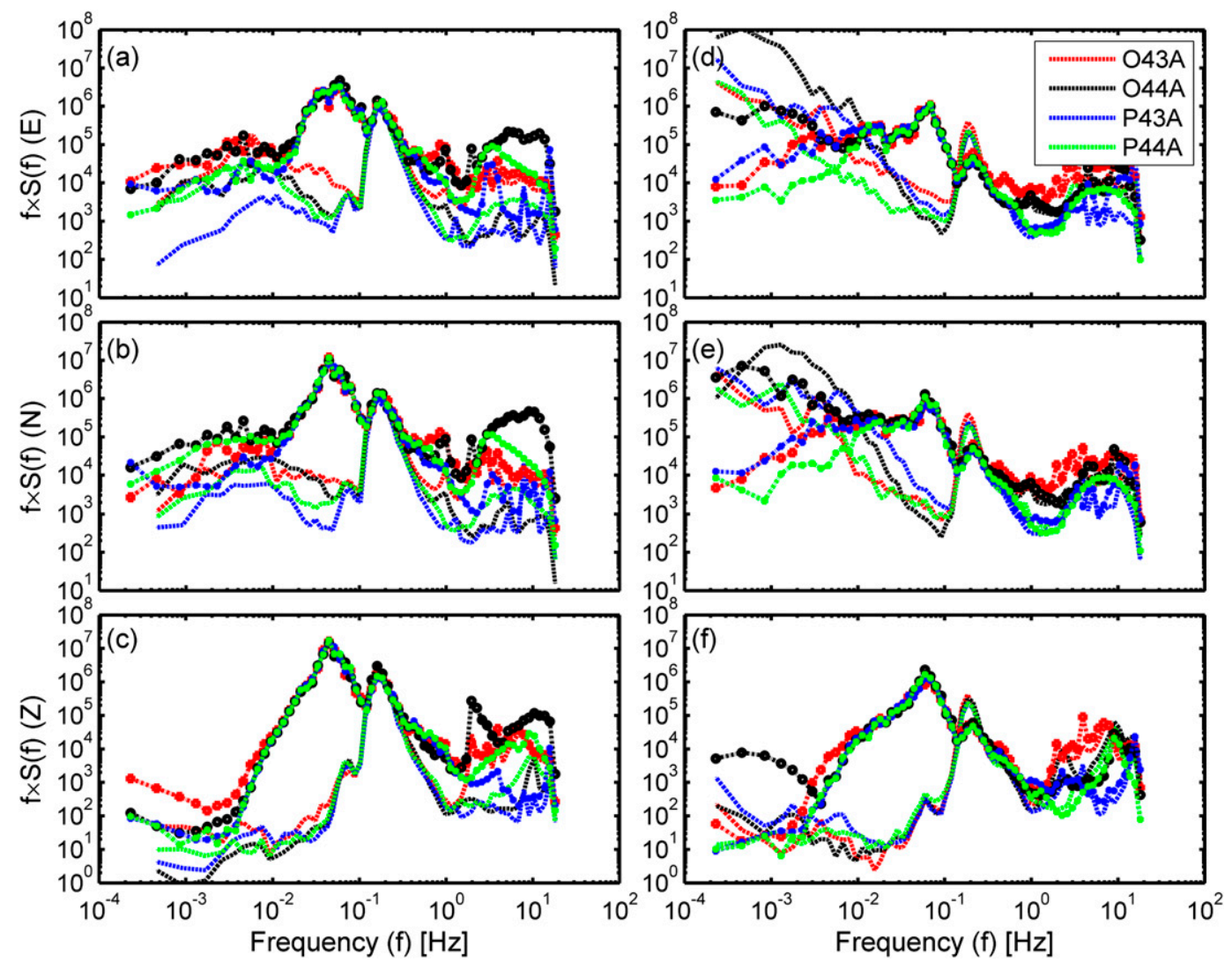

FIG. 6. Power spectra of data from the three-component broadband seismometers at four TA stations in central Illinois (where $\mathrm{E}$ denotes the west-east plane, $\mathrm{N}$ denotes the south-north plane, and $\mathrm{Z}$ denotes the vertical component): (a)-(c) data during 11 Nov 2012 and (d)-(f) data from 18 to 19 Apr 2013. Dashed lines denote data collected during a period of relatively quiescent winds, and lines with symbols show data from a period of high sustained and gust wind speeds. The spectra are shown as frequency $\times$ spectral energy density $[f \times S(f)]$ vs frequency $f$. Wind speed measurements at ASOS stations at the western edge of the domain (KSPI; Springfield, IL) and in the east of the study domain (KDEC; Decatur, IL) are shown in Table 2.

prior research on extratropical-cyclone gust factors (Table 1). The relationship between maximum GF and categorical estimates of 2-min sustained wind speed (the data are reported to the nearest knot) is described well by a power-law fit with the following parameters: scale factor $=5.91$ and power coefficient $=$ -0.499 .

3) Although intense wind events exhibit high spatial coherence, there is clear evidence for subsynopticscale variability, some of which is not captured even by the dense NWS ASOS network. Seismic data from the USArray exhibit well-defined spectral signatures that are associated with wind gusts (with variance maxima that appear to scale with wind-gust intensity) and thus indicate the potential to use these data to aid in spatially mapping and characterizing gust events. Further work is warranted to evaluate the generalizability of the results that are presented here and for this potential use to be realized.
Acknowledgments. This material is based upon work supported by the National Science Foundation (Grant 1019603) and the Incorporated Research Institutions for Seismology under their Cooperative Agreement EAR-1261681 with the National Science Foundation. The NCDC-6421 and ASOS datasets used herein were obtained from the National Climatic Data Center. The clarity of the presentation was greatly enhanced by the thoughtful comments of two anonymous reviewers.

\section{REFERENCES}

Agustsson, H., and H. Olafsson, 2004: Mean gust factors in complex terrain. Meteor. Z., 13, 149-155, doi:10.1127/ 0941-2948/2004/0013-0149.

Anderson, D. L., and Coauthors, 1976: The Viking Seismic Experiment. Science, 194, 1318-1321, doi:10.1126/science.194.4271.1318.

Azorin-Molina, C., and Coauthors, 2014: Homogenization and assessment of observed near-surface wind speed trends over Spain and Portugal, 1961-2011. J. Climate, 27, 3692-3712, doi:10.1175/JCLI-D-13-00652.1. 
Baigorria, G. A., J. W. Jones, and J. J. O’Brien, 2007: Understanding rainfall spatial variability in southeast USA at different timescales. Int. J. Climatol., 27, 749-760, doi:10.1002/joc.1435.

Bernhardt, J. E., and A. T. DeGaetano, 2012: Meteorological factors affecting the speed of movement and related impacts of extratropical cyclones along the U.S. east coast. Nat. Hazards, 61, 1463-1472, doi:10.1007/s11069-011-0078-0.

Blennow, K., M. Andersson, J. Bergh, O. Sallnas, and E. Olofsson, 2010: Potential climate change impacts on the probability of wind damage in a south Swedish forest. Climatic Change, 99, 261-278, doi:10.1007/s10584-009-9698-8.

Brasseur, O., 2001: Development and application of a physical approach to estimating wind gusts. Mon. Wea. Rev., 129, 5-25, doi:10.1175/1520-0493(2001)129<0005:DAAOAP>2.0.CO;2.

Bullock, J. M., S. M. White, C. Prudhomme, C. Tansey, R. Perea, and D. A. P. Hooftman, 2012: Modelling spread of British winddispersed plants under future wind speeds in a changing climate. J. Ecol., 100, 104-115, doi:10.1111/j.1365-2745.2011.01910.x.

Canada Transportation Development Centre, 1991: Wind and Wave Climate Atlas. MacLaren Plansearch Limited. [Available online at http://www.meds-sdmm.dfo-mpo.gc.ca/ isdm-gdsi/waves-vagues/atlas-eng.htm.]

Chandler, A. M., E. J. W. Jones, and M. H. Patel, 2001: Property loss estimation for wind and earthquake perils. Risk Anal., 21, 235-249, doi:10.1111/0272-4332.212108.

Changnon, S. A., Jr., 1980: Climatology of high damaging wind in Illinois. Illinois State Water Survey Rep. of Investigation 95, 44 pp. [Available online at http://webh2o.sws.uiuc.edu/pubdoc/RI/ ISWSRI-95.pdf.]

— 2009: Temporal and spatial distributions of wind storm damages in the United States. Climatic Change, 94, 473-482, doi:10.1007/s10584-008-9518-6.

_ 2011: Windstorms in the United States. Nat. Hazards, 59, 1175-1187, doi:10.1007/s11069-011-9828-2.

Cheng, C. S., G. L. Li, Q. Li, H. Auld, and C. Fu, 2012: Possible impacts of climate change on wind gusts under downscaled future climate conditions over Ontario, Canada. J. Climate, 25, 3390-3408, doi:10.1175/JCLI-D-11-00198.1.

— E. Eopes, C. Fu, and Z. Huang, 2014: Possible impacts of climate change on wind gusts under downscaled future climate conditions: Updated for Canada. J. Climate, 27, 1255-1270, doi:10.1175/JCLI-D-13-00020.1.

Choi, E. C. C., and F. A. Hidayat, 2002: Gust factors for thunderstorm and non-thunderstorm winds. J. Wind Eng. Ind. Aerodyn., 90, 1683-1696, doi:10.1016/S0167-6105(02)00279-9.

Coleman, J. S. M., and K. Klink, 2009: North American atmospheric circulation effects on Midwestern USA climate. Understanding Climate Change: Climate Variability, Predictability and Change in the Midwestern United States, S. C. Pryor, Ed., Indiana University Press, 156-168.

Cook, N. J., 1986: The Designer's Guide to Wind Loading of Building Structures: Part 1: Background, Damage Survey, Wind Data and Structural Classification. Butterworth-Heinemann, 383 pp.

Cusack, S., 2013: A 101 year record of windstorms in the Netherlands. Climatic Change, 116, 693-704, doi:10.1007/s10584-012-0527-0.

De Angelis, S., and P. Bodin, 2012: Watching the wind: Seismic data contamination at long periods due to atmospheric pressurefield-induced tilting. Bull. Seismol. Soc. Amer., 102, 1255-1265, doi:10.1785/0120110186.

Della-Marta, P. M., M. A. Liniger, C. Appenzeller, D. N. Bresch, P. Kollner-Heck, and V. Muccione, 2010: Improved estimates of the European winter windstorm climate and the risk of reinsurance loss using climate model data. J. Appl. Meteor. Climatol., 49, 2092-2120, doi:10.1175/2010JAMC2133.1.

Durst, C. S., 1960: Wind speeds over short periods of time. Meteor. Mag., 89, 181-187.

Easterling, D. R., and P. J. Robinson, 1985: The diurnal variation of thunderstorm activity in the United States. J. Appl. Meteor. Climatol., 24, 1048-1058, doi:10.1175/1520-0450(1985)024<1048: TDVOTA $>2.0 . \mathrm{CO} ; 2$.

Fink, A. H., T. Brücher, V. Ermert, A. Krüger, and J. G. Pinto, 2009: The European storm Kyrill in January 2007: Synoptic evolution, meteorological impacts and some considerations with respect to climate change. Nat. Hazards Earth Syst. Sci., 9, 405-423, doi:10.5194/nhess-9-405-2009.

Gardiner, B., H. Peltola, and S. Kellomaki, 2000: Comparison of two models for predicting the critical wind speeds required to damage coniferous trees. Ecol. Modell., 129, 1-23, doi:10.1016/ S0304-3800(00)00220-9.

Greenway, M. E., 1979: Analytical approach to wind velocity gust factors. J. Ind. Aerodyn., 5, 61-91, doi:10.1016/0167-6105(79)90025-4.

Groisman, P. Ya., 2002: Data documentation for data set 6421 (DSI-6421): Enhanced hourly wind station data for the contiguous United States. National Climatic Data Center Rep., 11 pp. [Available online at http://rda.ucar.edu/datasets/ds471.0/ docs/td6421-3.pdf.]

Hagemeyer, B. C., 1991: A low-tropospheric thermodynamic climatology for March through September: Some implications for thunderstorm forecasting. Wea. Forecasting, 6, 254-270, doi:10.1175/1520-0434(1991)006<0254:ALTTCF >2.0.CO;2.

He, Y. C., P. W. Chan, and Q. S. Li, 2013: Wind characteristics over different terrains. J. Wind Eng. Ind. Aerodyn., 120, 51-69, doi:10.1016/j.jweia.2013.06.016.

Hobbs, P. V., J. D. Locatelli, and J. E. Martin, 1996: A new conceptual model for cyclones generated in the lee of the Rocky Mountains. Bull. Amer. Meteor. Soc., 77, 1169-1178, doi:10.1175/ 1520-0477(1996)077<1169:ANCMFC > 2.0.CO;2.

Hoch, J., and P. Markowski, 2005: A climatology of springtime dryline position in the U.S. Great Plains region. J. Climate, 18, 2132-2137, doi:10.1175/JCLI3392.1.

Hoskins, B. J., and P. J. Valdes, 1990: On the existence of storm-tracks. J. Atmos. Sci., 47, 1854-1864, doi:10.1175/ 1520-0469(1990)047<1854:OTEOST>2.0.CO;2.

Huntington, T. G., 2006: Evidence for intensification of the global water cycle: Review and synthesis. J. Hydrol., 319, 83-95, doi:10.1016/j.jhydrol.2005.07.003.

Krayer, W. R., and R. D. Marshall, 1992: Gust factors applied to hurricane winds. Bull. Amer. Meteor. Soc., 73, 613-617, doi:10.1175/1520-0477(1992)073<0613:GFATHW>2.0.CO;2.

Kristensen, L., 1998: Cup anemometer behavior in turbulent environments. J. Atmos. Oceanic Technol., 15, 5-17, doi:10.1175/ 1520-0426(1998)015<0005:CABITE $>2.0$. CO;2.

_ M. Casanova, M. S. Courtney, and I. Troen, 1991: In search of a gust definition. Bound.-Layer Meteor., 55, 91-107, doi:10.1007/ BF00119328.

Lockridge, J. S., M. J. Fouch, and J. R. Arrowsmith, 2012: Seismicity within Arizona during the deployment of the EarthScope USArray Transportable Array. Bull. Seismol. Soc. Amer., 102, 1850-1863, doi:10.1785/0120110297.

Moore, P. H., and R. V. Osgood, 1985: Assessment of sugarcane crop damage and yield loss caused by high winds of hurricanes. Agric. For. Meteor., 35, 267-279, doi:10.1016/ 0168-1923(85)90089-9.

NOAA, 1998: Automated Surface Observing System (ASOS) user's guide. National Ocean and Atmospheric Administration 
Rep., 72 pp. [Available online at http://www.nws.noaa.gov/asos/ aum-toc.pdf.]

Paulsen, B. M., and J. L. Schroeder, 2005: An examination of tropical and extratropical gust factors and the associated wind speed histograms. J. Appl. Meteor., 44, 270-280, doi:10.1175/ JAM2199.1.

Peltola, H. M., 2006: Mechanical stability of trees under static loads. Amer. J. Bot., 93, 1501-1511, doi:10.3732/ajb.93.10.1501.

_ , V. P. Ikonen, H. Gregow, H. Strandman, A. Kilpelainen, A. Venalainen, and S. Kellomaki, 2010: Impacts of climate change on timber production and regional risks of windinduced damage to forests in Finland. For. Ecol. Manage., 260, 833-845, doi:10.1016/j.foreco.2010.06.001.

Pfahl, S., and H. Wernli, 2012: Spatial coherency of extreme weather events in Germany and Switzerland. Int. J. Climatol., 32, 1863-1874, doi:10.1002/joc.2401.

Pryor, S. C., and R. J. Barthelmie, 2013a: Assessing the vulnerability of wind energy to climate change and extreme events. Climatic Change, 121, 79-91, doi:10.1007/s10584-013-0889-y.

$\longrightarrow$, and — 2013b: Renewable energy resources-Ocean energy: Wind-wave-tidal-sea currents. Climate Vulnerability: Understanding and Addressing Threats to Essential Resources, R. Pielke, Ed., Academic Press, 65-81.

__ and _ 2014: Hybrid downscaling of wind climates over the eastern USA. Environ. Res. Lett., 9, 024013, doi:10.1088/ 1748-9326/9/2/024013.

—_ and Coauthors, 2009: Wind speed trends over the contiguous United States. J. Geophys. Res., 114, D14105, doi:10.1029/ 2008JD011416.

_ , R. J. Barthelmie, and J. T. Schoof, 2012: Past and future wind climates over the contiguous USA based on the North American Regional Climate Change Assessment Program model suite. J. Geophys. Res., 117, D19119, doi:10.1029/ 2012JD017449.

Rauber, R., J. Walsh, and D. Charlevoix, 2002: Severe and Hazardous Weather. Kendall/Hunt, 616 pp.

Ricciardulli, L., and P. D. Sardeshmukh, 2002: Local time- and space scales of organized tropical deep convection. J. Climate, 15, 2775-2790, doi:10.1175/1520-0442(2002)015<2775: LTASSO $>2.0 . \mathrm{CO} ; 2$.

Sanders, F., 1999: A short-lived cold front in the southwestern United States. Mon. Wea. Rev., 127, 2395-2403, doi:10.1175/ 1520-0493(1999)127<2395:ASLCFI >2.0.CO;2.
Segal, M., W. L. Physick, J. E. Heim, and R. W. Arritt, 1993: The enhancement of cold-front temperature contrast by differential cloud cover. Mon. Wea. Rev., 121, 867-873, doi:10.1175/ 1520-0493(1993)121<0867:TEOCFT > 2.0.CO;2.

Smith, B. T., T. E. Castellanos, A. C. Winters, C. M. Mead, A. R. Dean, and R. L. Thompson, 2013: Measured severe convective wind climatology and associated convective modes of thunderstorms in the contiguous United States, 2003-09. Wea. Forecasting, 28, 229-236, doi:10.1175/WAF-D-12-00096.1.

Thomas, B. C., and J. E. Martin, 2007: A synoptic climatology and composite analysis of the Alberta clipper. Wea. Forecasting, 22, 315-333, doi:10.1175/WAF982.1.

Thorarinsdottir, T. L., and M. S. Johnson, 2012: Probabilistic wind gust forecasting using nonhomogeneous Gaussian regression. Mon. Wea. Rev., 140, 889-897, doi:10.1175/MWR-D-11-00075.1.

Trifunac, M. D., 1970: Ambient vibration test of a thirty-nine story steel frame building. Earthquake Engineering Research Laboratory Rep. EERL 70-02, 40 pp. [Available online at http://authors.library.caltech.edu/26406/1/7002.pdf.]

Vautard, R., J. Cattiaux, P. Yiou, J. N. Thepaut, and P. Ciais, 2010: Northern Hemisphere atmospheric stilling partly attributed to an increase in surface roughness. Nat. Geosci., 3, 756-761, doi:10.1038/ngeo979.

Weggel, J. R., 1999: Maximum daily wind gusts related to mean daily wind speed. J. Struct. Eng., 125, 465-468, doi:10.1061/ (ASCE)0733-9445(1999)125:4(465).

Whiteman, C. D., X. D. Bian, and S. Y. Zhong, 1997: Low-level jet climatology from enhanced rawinsonde observations at a site in the southern Great Plains. J. Appl. Meteor., 36, 1363-1376, doi:10.1175/1520-0450(1997)036<1363:LLJCFE > 2.0.CO;2.

Wilczak, J. M., and A. J. Bedard, 2004: A new turbulence microbarometer and its evaluation using the budget of horizontal heat flux. J. Atmos. Oceanic Technol., 21, 1170-1181, doi:10.1175/1520-0426(2004)021<1170:ANTMAI > 2.0.CO;2.

Wong, C. J., and M. D. Miller, Eds., 2010: Guidelines for Electrical Transmission Line Structural Loading. ASCE, 204 pp.

Yu, B., and A. G. Chowdhury, 2009: Gust factors and turbulence intensities for the tropical cyclone environment. J. Appl. Meteor. Climatol., 48, 534-552, doi:10.1175/2008JAMC1906.1.

Zhou, Y., T. Kijewski, and A. Kareem, 2002: Along-wind load effects on tall buildings: Comparative study of major international codes and standards. J. Struct. Eng., 128, 788-796, doi:10.1061/(ASCE)0733-9445(2002)128:6(788). 